\title{
Tipos de modalidade e valores de futuro em -r- em português europeu: a proposta de Campos (1998) e alguns exemplos ilustrativos do texto narrativo Memorial do Convento de José Saramago
}

Palavras chave: futuro em -r-, português europeu, modalidade, futuro temporal, futuro modal

\section{Introdução}

Neste artigo, pretende-se trazer alguns contributos à descrição do conceito da modalidade, ou seja, dos valores modais associados, em português europeu, às formas do futuro em - $r$ - marcadoras da referência do futuro, tendo consciência da impossibilidade de levar a cabo um estudo exaustivo. Visa-se, assim, apresentar, a partir da proposta de Campos (1998), as características mais relevantes e os funcionamentos temporais e modais das formas do futuro em -r-e, também, exemplificar as observações com a análise das ocorrências das ditas formas nas sequências narrativas do texto Memorial do Convento (MdC) de José Saramago que constitui o corpus para a nossa análise.

\section{A associação das formas de futuro ao conceito de modalidade}

De modo geral, entende-se por modalidade a relação que o falante estabelece com o seu enunciado, isto é, o posicionamento que este falante assume diante do conteúdo do discurso que produz. Assim, para se realizar uma descrição linguística do fenómeno modalidade admite-se que a condição principal para a manifestação da modalidade nas línguas naturais é expressar as atitudes do falante. 
Desta forma, na hipótese sobre a subjetividade como base ou até condição para a expressão da modalidade nas línguas naturais, Palmer (1986) define modalidade como «a gramaticalização das atitudes subjetivas e opiniões do falante».

No que se refere à associação das formas do futuro ao conceito de modalidade, seria relevante referir que os estudos que tratam de modalidade tanto em português como em outras línguas românicas ( $c f$. entre muitos outros Fleishman, 1982; Culioli em Valentim, 2004; Bybee et al., 1994) demonstram que o conceito modalidade se parece particularmente resistente a uma definição homogénea. Ou, como se observa na Gramática da Língua Portuguesa (Oliveira, 2003: 245) «trata-se de um fenómeno de grande amplitude». Para os autores em Bybee et al. (1994), o futuro é «uma categoria modal semelhante às modalidades speaker oriented e epistémica», mas «com importantes implicações temporais» (Bybee et al., 1994: 280). Deste ponto de vista, a propriedade mais saliente do futuro românico em geral é a sua disponibilidade para expressar valores modais que coexistem com a função temporal. $\mathrm{Na}$ área das investigações linguísticas da língua portuguesa, um dos contributos para a descrição da tipologia de modalidade deve-se a Culioli (em Valentim, 2004: 153) que preconiza que os valores modais -que, com os valores temporais-aspetuais, confluem para a determinação de qualquer enunciado- resultam da localização de relação predicativa em relação ao sujeito enunciador ou a uma classe de sujeitos enunciadores.

De acordo com Fleischman (1982: 131-133), o futuro simples está em fase de recessão enquanto marcador temporal, pelo menos nas línguas como português, e se caracteriza por apresentar uma dicotomia entre o valor temporal de situar a ação descrita no futuro e o valor modal, cada vez mais presente. Assim, a autora individualiza o valor temporal 'pura futuridade' marcado pelas formas e construções do futuro. Também identifica os usos modais que se revelam numa série de 'aplicações modais', 'coloreados' da ideia de futuridade. Assim, como defende Fleischman (1982: 131-133) e se dá conta de línguas românicas em geral, os empregos modais do futuro sintético, nestas línguas, são: (i) o futuro 'volitivo' ('volitional future') que aparece em enunciados formalmente assertivos e interrogativos que, seguindo a ótica pragmática, realizam atos directivos (a força ilocutória do enunciado pode ir desde um comando até à de uma oferta ou sugestão); (ii) o futuro 'de probabilidade' ('expectativa razoável'), ou de 'suposição' que se pode referir a situações passadas ou presentes; (iii) o futuro 'atenuativo' que tem o efeito de atenuar quer asserções quer pedidos; (iiii) o futuro 'de indignação', em perguntas retóricas (E tu dirás que...); (iiiii) 
o futuro 'de comportamento característico'. Note-se que Fleischman realça que todos estes empregos modais do futuro sintético marcam sempre uma referência temporal futura mais ou menos nítida (ibid.). Fleischman observa também dois usos que não considera expressarem um valor modal, é o caso do futuro 'gnómico', que expressa 'asserções atemporais' e 'verdades eternas', e do futuro 'histórico', usado em narrações para expressar a posterioridade em relação a um ponto de referência temporal passado.

A complexidade do conceito de modalidade - e note-se que na cita referida a seguir, o termo modalidade aparece em plural- e a inserção deste conceito na linguística foi referida, além em outros estudos, também na obra Tempo, Aspecto e Modalidade de Campos (1997: 136) que observa:

As modalidades foram sempre um objecto de estudo privilegiado dos logicistas, muito mais do que dos linguistas. Mas as descrições propostas no domínio da lógica raramente recobrem o funcionamento das línguas naturais. Por essa razão, ao pretender manter-se numa perspectiva estritamente linguística, o linguista volta costas, mais ou menos explicitamente, às leis da lógica, que parecem não encontrar tradução no domínio da linguística. (Campos, 1997: 136)

\section{Os valores modais da forma em -r- do futuro do presente em português europeu}

No âmbito das investigações linguísticas da língua portuguesa, na obra Dever e Poder: um subsistema modal do português (1998) de Campos, foi abordado em particular o funcionamento linguístico da forma em - $r$ - do futuro do presente em português europeu. Campos observa uma dualidade no âmbito dos valores do futuro em português e, assim, dá conta do funcionamento destas formas verbais quando são portadoras do valor temporal e quando denotam o valor modal. Observa, assim, tanto o futuro temporal como o futuro modal. Nesta secção será dado relevo a algumas das observações referidas na obra de Campos (1998) sobre o funcionamento e os valores das formas em -r-do futuro do presente em português europeu com o objetivo de dar-se conta das propriedades semânticas caraterísticas deste paradigma verbal. Serão incluídos alguns exemplos de português europeu, ou seja, algumas sequências narrativas tomadas da obra Memorial do Convendo (MdC) de José Saramago para exemplificar e ilustrar cada um dos valores, tal como propostos na obra de Campos (1998). 
Campos (1998: 239-253), no primeiro lugar, observa o caso do futuro temporal, que, segundo a autora, corresponde «à construção de uma relação de posterioridade entre um determinado estado de coisas e um ponto de referência, sendo este, para o futuro simples, o tempo da enunciação, e, para o futuro composto é construído intratextualmente» (1998: 240). Reforça esta observação com o exemplo «Pela primeira vez na história da Igreja um Papa pregará, domingo, diante de uma assembleia de Luteranos» (ibid.). Está-se, como refere Campos (ibid.), no caso do futuro com valor temporal, diante de uma frase declarativa simples que para alguns linguistas exprime uma atitude neutra do locutor em relação ao que está a ser dito e é por tanto, não modal ${ }^{1}$. Porém, há teóricos ( $c f$. Bally,1932) que a este tipo de frases, ou seja, as frases declarativas simples associam a existência de um valor modal, neste caso, o valor modal 'assertivo', ou seja, o valor modal de asserção. Campos (1998: 241), ainda no âmbito dos valores temporais, observa assim o caso do futuro nos «enunciados que remetem para determinados universos de referência, nos quais o futuro gramatical se situa no domínio da probabilidade um, isto é, no domínio do 'certo', e não do não-certo». Assim, segundo Campos (1998: 241), este futuro gramatical, na escala de valores assertivos, se situa no domínio da probabilidade do 'certo'. A autora ilustra esta observação com o exemplo «Ao terceiro sinal serão cinco horas» (ibid.). São encontrados vários exemplos do uso do futuro em -r- temporal que se situa no domínio do 'certo' também no texto narrativo que constitui o corpus para a nossa análise. Apresenta-se, a seguir, algumas destas sequências narrativas:

(a) Quando, de manhã, Baltasar acordou, viu Blimunda deitada ao seu lado, a comer pão, de olhos fechados. Só os abriu, cinzentos àquela hora, depois de ter acabado de comer, E disse, Nunca te olbarei por dentro.

$(\mathrm{MdC}, 57)$

(b) O arquitecto ponderou, Mil frades, quinhentos frades, é muito frade, majestade, acabávamos por ter de fazer uma igreja tão grande como a de Roma, para lá poderem caber todos, Então, quantos, Digamos trezentos, e mesmo assim já vai ser pequena para eles a basílica que desenhei e está

1 Há autores que defendem que existe a tendência de ver a realidade como uma espécie de modalidade zero, assim, note-se, por exemplo, a hipótese de Ducrot que preconiza, como apresentado em Neves (2006: 152-156), que na noção de modalidade, se pode separar, ao menos teoricamente, o objetivo e o subjetivo, e, desse modo, que haja uma parte isolável da significação que seja pura e não modalizada descrição da realidade. Assim, parece que Ducrot defende a existência de enunciados não-modais. 
a ser construída, com muitos vagares, se me é permitido o reparo, Sejam trezentos, não se discute mais, é esta a minha vontade, Assim se fará, dando vossa majestade as necessárias ordens. Foram dadas. (MdC, 291)

(c) [...] coitada, já morreu, e não verá o maior e mais formoso monumento sacro da história, [...]

$(\mathrm{MdC}, 278)$

A análise dos enunciados ( $1 \mathrm{a}, \mathrm{b}$ e c) mostra que o futuro em -r-, ou seja, as formas olbarei, fará, verá concorrem para a construção do valor temporal de posterioridade. A partir do momento da enunciação se estabelece uma relação de posterioridade em relação àquele tempo localizador, ou seja, o tempo da enunciação. É de considerar também a atitude do sujeito enunciador destas sequências narrativas. O sujeito enunciador, nestes enunciado, visa, além de uma posterioridade, também uma validação, assim, as formas do futuro em -r-, nestes casos, são utilizadas com valor de certeza, situando-se, desta forma, no domínio do 'certo'.

A designação de outro emprego temporal do futuro em -r-, como refere Campos (1998: 241), é a designação do futuro como futuro histórico². A este «associa-se um valor modal que também se situa no domínio do 'certo'» (ibid.). Campos (1998: 241, 242), sublinha que esta designação é só uma das designações possíveis para caracterizar as ocorrências de futuro como as que ocorrem, por exemplo, em (2):

Ao contrário do que aconteceu com outras línguas românicas, uma diferente seleção do auxiliar para esta subclasse de verbos (por exemplo, em francês, être em vez de avoir) não persistirá em português, como é sabido. $\mathrm{Na}$ verdade, embora faltem também aqui ainda estudos mais extensos, é de crer que o desaparecimento de um pretérito perfeito composto com formas derivadas de ESSE latino tenha ocorrido quando as construções com baver e sobretudo ter (ver abaixo) + particípio passado gramaticalizaram como forma verbal composta.

(Brocardo, 2013: 114)

Nas narrativas históricas, onde aparecem formas do futuro com o valor de futuro histórico, há relações de posterioridade. Contudo, elas não justificam a utilização do futuro, visto que as relações de posterioridade poderiam ser

2 No âmbito do futuro histórico, faz-se, neste lugar, referência a uma observação de Cunha \& Cintra (1984: 458) que propõem como hipótese que o emprego do 'futuro histórico' em português europeu se deve a influência francesa e se nota em alguns escritores portugueses modernos. 
dadas no presente histórico ou no pretérito perfeito simples, pelo encadeamento dos acontecimentos em determinada ordem e/ou por conetores de valor temporal. Assim, o emprego do futuro, nestes casos, justifica-se como marcador de uma relação de posterioridade, não, ou não só, em relação aos acontecimentos citados no texto, mas sim, ou, sobretudo, «em relação a um ponto de referência que é, assim, construído e localizado intratextualmente» (Campos, 1998: 242). É construída, como refere a autora, uma mudança da perspetiva. Constrói-se, por tanto, «uma situação de enunciação fictícia» (ibid.). A partir desta um enunciador fictício narra, «como futuro em relação a ele próprio, aquilo que, para o enunciador origem, é um acontecimento do passado, validado e pertencendo ao domínio do 'certo'» (ibid.). No corpus que serviu para a nossa análise, no texto narrativo Memorial do Convento, não foi encontrado nenhum exemplo do emprego temporal do futuro em -r- com o valor temporal do futuro histórico.

Na contribuição teórica que vem de Campos (1998: 242-254), dá-se conta também do futuro com valores modais. O primeiro valor modal do futuro em -r- que se apresenta em Campos (1998: 243) é «o valor de suposição»³. É o valor que corresponde, como preconiza a autora, a um enfraquecimento da asserção, até marca a não-asserção. Campos (1998: 243) cita o exemplo «-E o amo? Onde está ele? -Andará lá p>rà Ribeira ${ }^{4}$ para ilustrar o valor de suposição da forma gramatical em -r-. O valor modal de suposição, como observa a autora, é um dos valores epistémicos que se aproxima do 'certo'e corresponde a um enfraquecimento da asserção. No que respeita a construção do valor modal que está em questão, a autora refere que o que o enunciador constrói neste tipo de enunciados é uma distância temporal 'falsa' ou 'fictícia', porque, na realidade, trata-se da distância modal, ou seja, a relação predicativa construída com o futuro em -r- com o valor de suposição refere «um estado de coisas contemporâneo da enunciação, ou que lhe é anterior e, neste último caso, usa-se

3 Quanto a este valor, Cunha \& Cintra (1984: 458) referem que exprime 'suposição' e chamam a atenção aos efeitos estilísticos opositivos «se o emprego do presente pelo futuro empresta ao facto a ideia de certeza, o uso do futuro pelo presente provoca efeito contrário, por transformar o certo em possível».

4 Em Boléo (1973: 13), refere-se o emprego denominado futuro 'dubitativo', quando o autor apresenta o diálogo «-E o amo? Onde está ele?-Andará lá p'rà Ribeira, mais o Ti' Martinho. Não tarda por í um credo!». Refere o autor que na pergunta, a locutora »emprega o presente, porque lhe interessa o facto objectivo: quer saber onde se encontra o marido. Mas o criado, que não tem a certeza responde com andará» (ibid.). Observa Boléo que «se confrontarmos esta frase com o diálogo, perfeitamente idéntico, [...] vemos que aquele futuro equivale a um presente mais um advérbio de dúvida. Andará não exprime futuridade, mas sim determinada atitude de espirito, ou seja a modalidade da acção: <anda talvez>» (ibid.). 
o futuro anterior» (Campos, 1998: 243). O valor de suposição deste futuro resulta «de o locutor não poder ou não querer assumir a validação da relação predicativa modalizada» (ibid.). A título destas observações de Campos, apresentam-se os exemplos do futuro em -r- com o valor de suposição, encontrado no texto narrativo analisado:

(3)

(a) [...], Não me cair um raio em cima, será pecado praguejar, mas alivia muito.

$(\mathrm{MdC}, 58)$

(b) Porém, hoje é dia de alegria geral, porventura a palavra será imprópria, porque o gosto vem de mais fundo, talvez da alma, olhar esta cidade saindo de suas casas, despejando-se pelas ruas e praças, descendo dos altos, juntando-se no Rossio para ver justiçar a judeus e cristãos-novos, a hereges e feiticeiros, fora aqueles casos menos correntemente qualificáveis, como os de sodomia, molinismo, reptizar mulheres e solicitálas, e outras miuçalhas passíveis de degredo ou fogueira.

(MdC, 50)

(c) [...] arremessados, e então era ver como velhos e novos remexiam na lama onde se enterrara um real, como tacteavam cegos o fundo das águas lodosas onde um real se afundara, enquanto as reais pessoas iam passando, passando, graves, severas, majestosas, sem abrirem um sorriso, porque também Deus não sorri, ele lá saberá porquê, talvez tenha acabado por se envergonhar do mundo que criou.

(MdC, 328)

O valor modal construído nas sequências narrativas ( $3 a, b$ e $c$ ) resulta do facto de o enunciador não querer ou não poder assumir a validação da relação predicativa, ou seja, não há certezas sobre uma determinada situação ou estado de coisas. As formas do futuro sintético será, será, saberá para além de marcarem uma distância modal, não marcam uma distância temporal e constroem só um valor modal. Esta constatação é evidenciada também pelo facto de que os acontecimentos linguísticos construídos, em termos temporais, são simultâneos ao tempo da enunciação.

Outro valor modal do futuro em -r-, observado em Campos (1998: 244), é o futuro com valor de certeza que reforça o valor de assertivo de enunciação e contém uma componente temporal. Associa-se às forças deônticas e às circunstâncias empíricas. Em palavras da autora, este emprego modal é um dos empregos modais quando o locutor, empregando o futuro gramatical em -r«constrói a certeza de que um determinado estado de coisas terá lugar, quer essa certeza tenha origem na própria vontade do locutor, quer ela se baseie 
numa crença e/ou resignação perante as imposições de uma força exterior» (Campos, 1998: 244). Porém, a autora não deixa de ter em conta a componente temporal que é coexistente, o que se deve ao facto, como se explica (ibid.), de a localização temporal do acontecimento linguístico ter lugar num momento posterior ao tempo da enunciação. $O$ futuro com este valor denota o dever, a obrigação, tem valor de imperativo e na literatura linguística recebeu várias denominações, como o futuro volitivo, o futuro de promessa, o futuro profético, o futuro gnómico, o futuro compulsivo, o futuro sugestivo, entre outros'. É de sublinhar, que, segundo Campos (1998: 245), «contrariamente ao futuro de suposição, o futuro com valor de certeza acentua a certeza de que uma coisa acontecerá» e reforça, assim, o valor assertivo do enunciado. A autora (ibid.) verifica, a base de exemplo «depois verás quem tinha razão», que ao valor temporal de 'depois verás', se associa ao valor modal 'de certeza'. No caso «farás o que eu te digo», constroem-se os mesmos valores temporal e modal e trata-se dum reforço do valor imperativo. Como refere Campos, «no momento da enunciação, o locutor tem a 'certeza' sobre a realização do acontecimento linguístico num momento posterior ao agora de enunciação» (ibid.). Quanto à diferença do emprego entre as formas em -r-e as formas de imperativo, a autora realça, que no caso do futuro, na relação intersubjetiva locutor-interlocutor, o papel deste último é mínimo, não havendo nenhuma imposição. No caso do imperativo, também há imposição. Parece que em ambos os empregos já está tudo decidido, sem considerar nem a situação nem a opinião do interlocutor. Apresenta-se, a seguir, uma sequência narrativa (4) do nosso corpus que inclui, entre outras, também as formas do futuro em -r(irás construindo, entrançarás, irás, procurarás, deverás, comprarás, mercarás, baverás) que, nesta sequência, ocorrem com o valor modal deôntico de obrigação, aproximando-se da força ilocutória do imperativo. Assim, em (4) pode-se verificar que as formas do futuro em -r- estão associadas à interações discursivas entre as diferentes personagens da história. Note-se também que na relação intersubjetiva locutor-interlocutor, o papel deste último é mínimo, ou seja, não se considera nem a situação nem a atitude do interlocutor.

5 Said Ali (1923: 107-113), por exemplo, denomina este uso como futuro compulsivo e assinala «este futuro compulsivo [...] pode ser ou categórico ou simplesmente sugestivo. O tipo categórico exprime uma ordem dada no tempo presente, contando-se que será cumprida. É linguagem mais enérgica que o modo imperativo, pois que não faz o mínimo cado da vontade do individuo com quem se fala» (ibid.). Boléo, por sua vez, (1973: 14-15) observa o caso do futuro 'intimativo' ou de obrigação moral que equivale, segundo este autor, a um auténtico imperativo. 


\section{(4)}

Disse Baltasar, E a máquina de voar, como a farei, Como a tínhamos começado, [...] irás construindo de baixo para cima, [...], entrançarás o vime e o ferro, imagina que estás ligando penas a ossos, já te disse, virei sempre que puder, para comprares o ferro irás a este lugar, procurarás nos vimiais do termo o vime de que precisas, e ao açougue irás comprar as peles para os foles da máquina, eu te direi como deverás curti-las e cortá-las, [...] e tens aqui mais este dinheiro, comprarás um burro, sem ele como transportarias todos os materiais necessários, e também mercarás uns ceirões grandes, mas haverás sempre à mão ervas ou palhas para que possas esconder o que trouxeres dentro deles, lembrem-se de que toda esta nossa obra terá de ser feita em absoluto segredo, [...] e se alguém aí vier com perguntas, dirão que estão a guardar a quinta por ordem de el-rei, [...]

$(\mathrm{MdC}, 150,151)$

Outro valor modal do futuro em -r-, observado em Campos (1998: 246), é o futuro com valor de atenuação que corresponde a um valor de asserção e marca enfraquecimento da tensão intersubjetiva ${ }^{6}$. Como refere Campos, o futuro com valor de atenuação ocorre sobretudo com os verbos enunciativos. Marca-se, com o emprego do futuro com valor de atenuação, como se dá conta em Campos (1998: 246), «uma distanciação do enunciador em relação a uma asserção da qual o responsável é o interlocutor, e não ele próprio». É interessante referir a diferença entre o futuro de suposição e o futuro de atenuação, correspondendo o primeiro a um valor não assertivo e o segundo marcando um valor de asserção estrita. Como refere Campos (1998: 247), o 'direi' não se pode substituir por 'talvez diga', porque ao dizer 'direi que', o enunciador-locutor está 'efectivamente a dizer que... '. No caso deste futuro, a própria enunciação se projeta, abstratamente, num tempo posterior ao tempo de enunciação. Ilustra-se estas afirmações com duas sequências narrativas ( $5 \mathrm{a}$ e b) do texto Memorial do Convento nas quais o enunciador, a empregar as formas do futuro em -r- (diremos nós e direi), constrói uma relação predicativa que se localiza temporalmente no momento da enunciação e não depois do dito momento.

6 Para Cunha \& Cintra (1984: 457) este uso é a forma polida de presente. Para Boléo (1973: 13), por sua vez, «o futuro imperfeito é mais polido e serve para traduzir expressões de modéstia ou cortesia, emprego esse principalmente popular e que apresenta, portanto, aspecto sociolinguístico». 
(5)

(a) Durante uma semana, todos os dias, sofrendo o vento e a chuva pelos caminhos alagados de S. Sebastião da Pedreira, o músico foi tocar duas, três horas, até que Blimunda teve forças para levantar-se, sentava-se ao pé do cravo, pálida ainda, rodeada de música como se mergulhasse num profundo mar, diremos nós, que ela nunca por aí navegou, o seu naufrágio foi outro.

(MdC, 192)

(b) [...] Porque come Blimunda pão antes de abrir os olhos de manhã, Sim, Se o vieres a saber um dia, será por ela, por mim não, Mas sabe a razão, Sei, E não ma diz, Só te direi que se trata de um grande mistério, voar é uma simples coisa comparando com Blimunda.

(MdC, 66)

Note-se que, nos exemplos ( 5 a e $b$ ), o enunciador a empregar as formas do futuro em -r- do verbo enunciativo dizer (diremos nós e direi) projeta um determinado estado de coisas presente num momento posterior à enunciação. $\mathrm{O}$ objetivo de tal enunciação é o propósito de atenuar a ideia de que algo está a acontecer, i.e., que o enunciador, a enunciar que 'dirá', 'já está a dizer'.

\section{Notas conclusivas}

Como resumo das observações acima apresentadas, poder-se-á sumarizar, então, que, em português europeu, quanto ao futuro em -r- e os seus valores temporais, foi verificado em Campos (1998) que o futuro temporal contém uma componente modal que, embora não predominante, não pode ser evacuada. Quanto aos empregos modais, ainda no âmbito do português europeu, evidencia-se na mesma obra (Campos, 1998) que, considerando a escala contínua de valores assertivos, os valores modais marcados pela forma em -r- do futuro podem ser representados nesta escala de forma que o futuro de suposição se situa num ponto próximo de, ou coincidente com o polo zero (o polo da não asserção); o futuro de certeza, por sua vez, situa-se num ponto que tende para o polo um (o polo da asserção, positiva ou negativa). Foi referido também outro valor modal do futuro em -r-, observado em Campos (1998: 246), que é o futuro com valor de atenuação que corresponde a um valor de asserção e marca enfraquecimento da tensão intersubjetiva. As observações de Campos (1998) foram exemplificadas com alguns exemplos de português europeu, ou seja, algumas sequências narrativas tomadas da obra Memorial do Convento de José Saramago que constituiu o corpus de análise para ilustrar e verificar cada um dos valores, tal como propostos na obra de 
Campos (1998). A análise das formas do futuro em -r- nas sequências narrativas analisadas comprovou a proposta da classificação dos usos e valores do estudo de Campos (1998).

\section{Bibliografia}

Bally, C. (1932): Linguistique générale et linguistique française. Bern: Francke.

Boléo, M. P. (1973): Os valores temporais e modais do futuro imperfeito e do futuro perifrástico em português. Separata de Biblos - vol. XLI. Coimbra: Biblioteca da Universidade.

Brocardo, M. T. (2013): O pretérito perfeito composto - origem e evolução histórica. Em: Markič, Jasmina / Correia, Clara Nunes (2013): Descrições e Contrastes - Tópicos de Gramática Portuguesa com Exemplos Contrastivos Eslovenos/Opisi in primerjave. Poglavja iz slovnice portugalskega jezika s kontrastivnimi ponazoritvami v slovenščini. Ljubljana. Znanstvena založba Filozofske fakultete Univerze v Ljubljani.

Bybee, J. L. et al. (1994): The Evolution of Grammar. Tense, Aspect, and Modality in the Languages of the World. Chicago: University of Chicago Press.

Campos, M. H. Costa \& Xavier, M. F. (1991): Sintaxe e Semântica do Português. Lisboa: Universidade Aberta.

Campos, M. H. Costa (1997): Tempo, Aspecto e Modalidade. Estudos de Linguística Portuguesa. Porto: Porto Editora.

Campos, M. H. Costa (1998): DEVER e PODER. Um subsistema modal do Português. Lisboa: Fundação Calouste Gulbenkian.

Cunha, C. \& Cintra, L. L. (1984): Nova Gramática do Português Contemporâneo. Lisboa: Edições João Sá da Costa.

Fleischman, S. (1982): The Future in Thought and Language. Diacbronic Evidence from Romance. Cambridge: Cambridge University Press.

Neves, M. H. de Moura (2006): Gramática e Texto. São Paulo: Contexto.

Oliveira, F. (2003): «Modalidade e modo». Em: Mateus, M. H. et al. Gramática da Lingua Portuguesa ( $5^{\mathrm{a}}$ ed.). Lisboa: Caminho, 242-272.

Palmer, F. R. (1986): Mood and Modality. Cambridge: Cambridge University Press.

Said Ali, M. (1923): Formação de palavras e syntaxe do portuguez bistorico. São Paulo - Cayeiras - Rio: Companhia Melhoramentos de S. Paulo (Weiszflog Irmãos). 
Valentim, H. T. (2004): Um estudo semântico-enunciativo de predicados subjectivos do português. Dissertação de Doutoramento. Lisboa: Universidade Nova de Lisboa.

\section{Corpus}

Saramago, José ([1994] 2006): Memorial do Convento. 39. edição. Lisboa: Caminho. 
Blažka Müller Pograjc

University of Ljubljana

\section{Types of Modality and Values of Future in Contemporary European Portuguese - A Proposal of Campos (1998) and some Exemples from the Narrative Text Memorial do Convento of José Saramago}

Keywords: 'o futuro em -r-', European Portuguese, modality, temporal future, modal future

The starting point for this article is the initial universally acknowledged consideration that the forms of future tenses, in natural languages and as well in contemporary European Portuguese, are associated, in addition to the temporal values, also to the modal ones. In view of the article's outcomes, it seems safe to conclude that in contemporary European Portuguese, the future tense, denominated futuro em -r-, considering its temporal values and uses, implicates always a modal component that cannot be evacuated.

Considering the theoretical framework of Campos (1998), it can also be claimed that, in the light of the continuous scale of assertive values (escala continua de valores assertivos), the modal values, marked by futuro em - $r$-, can be represented in this scale so that the 'future of supposition' is situated at a point near to, or coincident with the pole zero - the pole of non-assertion. The 'future of certainty', in turn, can be represented as situated at a point which tends to the pole one - the pole of the assertion, positive or negative. The observations of Campos (1998) were exemplified by some examples of European Portuguese, that is, some narrative sequences taken from the work of José Saramago's Memorial do Convento, which constituted the corpus of analysis, to illustrate and verify each of the values, as proposed in Campos (1998). The analysis of the forms of the 'futuro em - $r$-' in the narrative sequences analyzed proved the classification of the uses and values of the Campos proposal (1998). 
Blažka Müller Pograjc

Univerza v Ljubljani

\section{Tipi modalnosti in vrednosti prihodnjikov v sodobni evropski portugalščini - teoretski okvir Camposove (1998) in nekaj ilustrativnih primerov iz pripovednega besedila Zapis o samostanu Joséja Saramaga}

Ključne besede: portugalski sintetični prihodnjik futuro em -r-, evropska portugalščina, modalnost, časovni prihodnjik, modalni prihodnjik

Avtorica pričujočega članka skuša podati nekaj prispevkov k opisu koncepta modalnosti oz. znova osvetliti problematiko modalnih vrednosti, ki jih v sodobni evropski portugalščini označujejo oblike prihodnjikov - lingvistični označevalci prihodnostne časovne reference. Izhodišče za takšno razmišljanje je začetna že splošno priznana in sprejeta ugotovitev, da oblike prihodnjikov označujejo tako časovno kot tudi ali pa morda zlasti modalno vrednost.

Na podlagi zapisanega v članku lahko ugotovitve strnemo v trditvi, da v skladu s teoretičnimi zapisi, podanimi v Campos (1998), portugalski sintentični prihodnjik oz. futuro em -r-zmeraj označuje modalno komponento, ki ne more biti spregledana. Tako se časovni prihodnjik na -r- v povezavi s časovnimi vrednostmi na lestvici asertivnih vrednosti (a escala contínua de valores assertivos) postavlja v območje 'gotovosti' (Ao terceiro sinal serão cinco horas) in vsebuje modalno komponento ('gotovosti'), ki je, četudi ne prevladujoča, vedno prisotna. Kar se tiče modalnih rab, pa na podlagi teoretskih izhodišč Camposove (1998) avtorica opaža, da se, če upoštevamo lestvico asertivnih vrednosti, modalne vrednosti, ki jih signalizirajo oblike prihodnjika na -r-, na to lestvico umeščajo tako, da se pribodnjik predvidevanja (o futuro de suposição) postavlja na tisti konec lestvice, ki sovpada z njenim ničelnim polom - polom nepotrditve. 
Na drugi strani pa se pribodnjik gotovosti (o futuro de certeza), povezan z deontičnimi silami in empiričnimi okoliščinami, umešča na točko, ki se nagiba k polu ena - $\mathrm{k}$ polu potrditve -, bodisi trdilne bodisi nikalne. Prav tako avtorica opisuje še eno modalno vrednost prihodnjika na -r-v portugalščini, ki jo opaža Camposova (1998: 246), in sicer prihodnjik z vrednostjo 'omilitve' (atenuação), ki ustreza asertivni vrednosti potrditve, vendar pa označuje oslabitev intersubjektivne napetosti. Ugotovitve Camposove (1998) so v članku podkrepljene z nekaj primeri iz evropske portugalščine, in sicer s sekvencami iz pripovednega besedila Zapis o samostanu Joséja Saramaga, ki predstavlja korpus za analizo, s katero so se osvetlile in potrdile vrednosti, kot jih omenja in opisuje Camposova (1998). Analiza oblik prihodnjika na -r-v obravnavanih sekvencah je potrdila primernost predloga klasifikacije rab in vrednosti, kot jih v svojem teoretskem delu predlaga Camposova (1998). 